\title{
CURRÍCULO E SABER OBJETIVO NA ORGANIZAÇÃO DO ENSINO NAS SALAS MULTISSERIADAS
}

\author{
Maria Cristina dos Santos ${ }^{1}$ \\ Klívia de Cássia Silva Nunes²
}

\section{RESUMO}

As salas multisseriadas são formadas por turmas heterogêneas de alunos que se encontram em nível de conhecimento, ano de escolaridade e idade diferentes, no mesmo espaço, e com um único docente. Geralmente a organização do ensino nestas salas se dá seguindo o mesmo modelo das salas seriadas, o que acaba por conduzir a uma separação dos alunos por série e ou ano de escolaridade e à elaboração de diversos planos de aula, o que pode levar a não se atingir todos os objetivos educativos e um acesso precário aos conteúdos curriculares previstos para cada série. Este artigo tem por objetivo refletir sobre a organização curricular nas salas multisseriadas visando a transmissão e aquisição do saber objetivo a partir do aporte teórico-metodológico da Pedagogia Histórico-Crítica, teoria pedagógica de base materialista histórico dialética. Aventamos a possibilidade de organizar o trabalho pedagógico nessas salas a partir de um currículo único em que os conteúdos trabalhados sejam os mesmos, variando o teor e o aprofundamento das atividades de acordo com o nível de desenvolvimento de cada criança. A questão norteadora deste trabalho é: como organizar o ensino em salas multisseriadas de forma a contribuir com o saber objetivo mediado pela aquisição do conhecimento científico, que possibilite a ascensão do pensamento do abstrato para o concreto independentemente do nível de conhecimento e idade que os alunos se encontram? Trata-se de um artigo teórico elaborado a partir de estudo do referencial pedagógico marxista e de observações e anotações de pesquisas realizadas pelas autoras sobre trabalho docente e ensino em escolas no meio rural. Buscamos elaborar uma resposta, ainda que provisória, como forma de contribuir com as discussões sobre o ensino nas salas multisseriadas que possibilite a formação social e consciente do filho do trabalhador do campo, para que ele se perceba como cidadão de direitos e deveres, que seja capaz de se reconhecer enquanto protagonista da história e potencializador da transformação social.

\footnotetext{
1 Doutorado em Educação. Professora Associada do Departamento de Educação e do Programa de Pós-Graduação em Educação/UFSCar campus São Carlos. São Paulo, Brasil. Membro do Grupo de Estudos e Pesquisas em Educação no Campo e líder do Grupo de Estudos e Pesquisas sobre Trabalho, Política e Educação Escolar/UFSCar. Orcid iD: http://orcid.org/0000-0003-3130-9433. E-mail: cbezerra@ufscar.br

2 Doutorado em Educação. Professora da Universidade Federal de Uberlândia. Campus Tocantinópolis. Minas Gerais, Brasil. Membro do Grupo de Estudos e Pesquisas sobre Educação no Campo/UFSCar. Membro do Grupo de Pesquisa História da Educação e Marxismo/UFT. Membro do Grupo de Estudos e Pesquisas sobre Trabalho, Política e Educação Escolar/UFSCar. Orcid iD: https://orcid.org/0000-0001-5264-9598. E-mail: klivianunes67@gmail.com
} 
Palavras-chave: Educação no Campo. Pedagogia Histórico-Crítica. Currículo Escolar. Escolas Multisseriadas.

\title{
CURRICULUM AND OBJECTIVE KNOWLEDGE INTO THE MULTIGRADE SCHOOLS' SET UP
}

\begin{abstract}
The multiseries classrooms are made up of heterogeneous classes of students who are at a different level of knowledge, schooling and age, in the same space, and with a single teacher. Generally, the organization of teaching in these classrooms follows the same model as in the serial classrooms, which leads to the separation of students by grade and/or year of schooling and the elaboration of different lesson plans, which can lead to not being able to attend achieve all educational objectives and precarious access to the curriculum content foreseen for each grade. This article aims to reflect on the curricular organization in the multiserial rooms aiming at the transmission and acquisition of objective knowledge from the theoretical-methodological support of Historical-Critical Pedagogy, a dialectical historical materialistic pedagogical theory. We suggested the possibility of organizing the pedagogical work in these rooms based on a unique curriculum in which the contents worked are the same, varying the content and the depth of the activities according to the level of development of each child. The guiding question of this work is: how to organize teaching in multiseries rooms in order to contribute with objective knowledge mediated by the acquisition of scientific knowledge, which allows the rise of thought from abstract to concrete, regardless of the level of knowledge and age that students meet? This is a theoretical article based on a study of the Marxist pedagogical framework and observations and notes of research carried out by the authors on teaching work and teaching in schools in rural areas. We seek to elaborate a response, albeit provisional, as a way to contribute to the discussions on teaching in the multiserial rooms that enable the social and conscious formation of the son of the field worker so that he perceives himself as a citizen of rights and duties, who is capable to recognize itself as a protagonist of history and a potential for social transformation.
\end{abstract}

Keywords: Rural Education. Historical-Critical Pedagogy. School Curriculum. Multigrade School.

\section{CURRÍCULO Y CONOCIMIENTO OBJETIVO EN LA ORGANIZACIÓN DE LA ENSEÑANZA EN ESCUELAS MULTIGRADO}

\section{RESUMEN}

Las aulas multiseriales están formadas por clases heterogéneas de alumnos de distinto nivel de conocimiento, escolaridad y edad, en un mismo espacio y con un solo profesor. Generalmente, la organización de la docencia en estas aulas se lleva a cabo siguiendo el mismo modelo que en las aulas seriadas, lo que conlleva la separación de los alumnos por grado y / o curso escolar y la elaboración de diferentes planes de estudio, lo que puede llevar a no poder para asistir, lograr todos los objetivos educativos y precario acceso a los contenidos curriculares 
previstos para cada grado. Este artículo tiene como objetivo reflexionar sobre la organización curricular en las salas multiseriales con miras a la transmisión y adquisición de conocimientos objetivos a partir del soporte teórico-metodológico de la Pedagogía Histórico-Crítica, una teoría pedagógica histórico-materialista dialéctica. Sugerimos la posibilidad de organizar el trabajo pedagógico en estas aulas partiendo de un currículo único en el que los contenidos trabajados sean los mismos, variando el contenido y la profundidad de las actividades según el nivel de desarrollo de cada niño. La pregunta orientadora de este trabajo es: cómo organizar la docencia en aulas multiseriales para contribuir con un conocimiento objetivo mediado por la adquisición de conocimiento científico, que permita el ascenso del pensamiento de lo abstracto a lo concreto, independientemente del nivel de conocimientos y la edad que los estudiantes żse encuentran? Se trata de un artículo teórico basado en un estudio del marco pedagógico marxista y las observaciones y apuntes de las investigaciones realizadas por los autores sobre la labor docente y la docencia en las escuelas del medio rural. Buscamos elaborar una respuesta, aunque provisional, como una forma de contribuir a las discusiones sobre la docencia en las salas multiseriales que posibiliten la formación social y consciente del hijo del trabajador de campo para que se perciba como ciudadano de derechos y deberes, que es capaz de reconocerse como protagonista de la historia y potencial de transformación social.

Palabras clave: Educación en el Campo. Pedagogía Histórico-Crítica. Currículum Escolar. Escuelas Multiseriales.

\section{INTRODUÇÃO}

As salas multisseriadas são formadas por turmas heterogêneas de alunos que se encontram em nível de conhecimento, ano de escolaridade e idade diferentes, em um mesmo espaço sob a responsabilidade de um único docente. Esse modelo de organização escolar pode ocorrer em áreas urbanas e rurais, entretanto, a maior incidência delas se dá nas escolas no meio rural. Essa característica fundante desse tipo de organização escolar tem sido vista como um desafio aos professores, motivo de muitas críticas e resistências à sua manutenção, no entanto, está revestida de possibilidades de avanços no trabalho pedagógico desde que compreendida como uma potencialidade (PARENTE, 2014; HAGE, 2008; 2014; ARROYO, 2010).

Vamos refletir sobre a organização curricular da escola multisseriada nos somando a outros pesquisadores e professores que tem dedicado esforços no sentido de problematizar o ensino que ocorre nessas salas (PARENTE, 2014; MARSIGLIA e MARTINS, 2014; HAGE, 2014) e, para tal, partimos do pressuposto de que a transmissão do conhecimento sistematizado é um ato intencional, fundamental para a formação humana 
(SAVIANI, 2011). A escola é a instituição social responsável pela difusão e acesso ao conhecimento historicamente produzido pelo conjunto dos homens, na sua forma mais elaborada como a ciência, a arte, a filosofia e que deve ser transmitido às novas gerações (SAVIANI, DUARTE, 2012).

A questão norteadora que nos move na elaboração deste trabalho é: como organizar o ensino em salas multisseriadas de forma a contribuir com a disseminação e aquisição do saber objetivo que possibilite a ascensão do pensamento abstrato para o concreto independentemente do nível de conhecimento e idade que os alunos se encontram? Tomando por base as elaborações teórico-práticas de autores e pesquisadores da Pedagogia Histórico-Crítica a respeito da escola e sua função social, nos inserimos nas discussões a respeito da organização do ensino para as salas multisseriadas acreditando que o trabalhador do campo e seus descendentes, de posse do conhecimento sistematizado que é transmitido pela escola, terão mais elementos para sua participação enquanto cidadão de direitos e deveres, capazes de se reconhecer como agentes da história e da transformação social.

A educação é um fenômeno próprio dos seres humanos, é a construção do pensamento social em situações concretas da realidade a partir da produção e reprodução da própria existência (SAVIANI, 2008, p. 94). É por meio do trabalho que o homem transforma a natureza em função de suas necessidades, resultando desse processo um mundo humano, o mundo da cultura. O trabalho é uma ação intencional, planejada, adequada a finalidades e, tal qual o trabalho, a educação também é uma atividade exclusivamente humana. Se o desenvolvimento da existência humana depende da produção de seu sustento a partir da produção material da sua sobrevivência, concomitante a isso se produz também as ideias, conceitos, valores, símbolos, hábitos, atitudes e habilidades, produz-se saber, saber sobre a natureza, produz-se a cultura. A educação se vincula a esse segundo aspecto do trabalho, o da produção das ideias, sendo ela a responsável pela sua sistematização e difusão (SAVIANI, 2018). 
No processo de produção da própria existência se dá a formação do homem, um processo educativo que

\begin{abstract}
evidencia a relação histórica e ontológica entre a natureza da educação e a natureza dos próprios homens. Estes necessitam produzir continuamente sua própria existência por meio das atividades de trabalho e precisam também aprender a produzir essa existência, o que nos permite concluir que tal processo é educativo (LAVOURA; MARTINS, 2017, p. 537).
\end{abstract}

Assim, o que não é garantido pela natureza é produzido historicamente pelo homem, incluindo os próprios homens (SAVIANI, 2008), portanto, é um processo educativo, como afirmam Lavoura e Martins (2017), visto que o homem precisa assimilar elementos culturais para que se torne humano e, concomitantemente, precisa descobrir formas para atingir esse objetivo (SAVIANI, 2008). Desta forma, o trabalho também adquire um caráter educativo, que, por sua vez é definido por Saviani como "[...] ato de produzir, direta e intencionalmente, em cada indivíduo singular, a humanidade que é produzida histórica e coletivamente pelo conjunto dos homens" (SAVIANI, 2008, p. 13).

É nessa definição que encontramos a especificidade da educação escolar que está diretamente relacionada com a transmissão do saber sistematizado, do conhecimento científico. À escola, na sociedade moderna, foi delegada a tarefa, diríamos mais, a responsabilidade pela socialização dos elementos culturais, produzidos historicamente pela humanidade e que por meio do trabalho educativo escolar, devem ser repassados para as novas gerações.

Isso remete ao trabalho educativo, que, de acordo com Saviani (2008), deve, de um lado, identificar os elementos culturais que precisam ser assimilados pelos indivíduos e, de outro lado, encontrar as formas mais adequadas para que os objetivos do ato de aprender sejam efetivados.

Nesse sentido, o presente trabalho procura contribuir com fundamentos teórico-práticos abstraídos de observações de pesquisas sobre duas temáticas relacionadas ao cotidiano das escolas rurais: trabalho docente e práticas de ensino, realizadas pelas autoras no decorrer dos 
últimos três anos, para o (re)pensar o ensino em salas multisseriadas. Na primeira parte discutimos a necessária articulação entre o trabalho educativo e a socialização do saber sistematizado ao tratar do currículo da escola no campo a partir dos enunciados da Pedagogia Histórico-Crítica. Em seguida, abordamos a organização curricular das salas multisseriadas demonstrando como vem acontecendo o ensino nessas salas e indicando possibilidades de um salto qualitativo no processo de ensino e aprendizagem com base em uma concepção pedagógica contra-hegemônica.

\section{CURRÍCULO DA ESCOLA NO CAMPO E A PEDAGOGIA HISTÓRICO-CRÍTICA}

A expressão "currículo escolar" é bastante difundida entre os educadores de modo que escolas, profissionais do ensino e sistemas escolares têm familiaridade com o termo. O objeto específico da educação escolar tem duas frentes indissociáveis: a identificação dos conhecimentos que necessitam ser apropriados pelas novas gerações e, a descoberta das formas mais adequadas para promover essa apropriação. De acordo com Lavoura e Martins (2017, p. 537), o trabalho educativo consiste na articulação dialética entre conteúdo e forma na socialização do saber sistematizado que, por ser ato intencional, é norteado por finalidades (objetivos a atingir), coloca em movimento os processos de ensino (transmissão), fundada na atividade do professor e aprendizagem (apropriação), a atividade do aluno.

O conhecimento que é transmitido pela escola não é qualquer tipo de conhecimento. Tem a ver com conhecimento elaborado, sistematizado, dosado, sequenciado de modo que a criança passe gradativamente de seu não domínio ao seu domínio. Disso depreende-se o currículo. O currículo diz respeito ao conteúdo da educação, ao que se deve fazer para disseminar tal e qual conhecimento, ou seja, para que a instituição escolar atinja seu objetivo, é a escola funcionando (SAVIANI, 2016b). Mas, de acordo com 
Saviani (2016b, p. 57), não se trata de toda e qualquer atividade: "currículo é o conjunto das atividades nucleares 3 desenvolvidas pela escola".

Currículo é um documento que orienta o trabalho pedagógico e como tal, "se configura a partir de uma compreensão de sociedade e almeja formar indivíduos com intencionalidade e numa determinada direção" (ORSO; MALANCHEN, 2016, p. 02), ou seja, todo currículo aponta um caminho, indica um tipo de ser humano que se quer forjar e traz implícito, um modelo de sociedade. Desta forma o currículo envolve

a expressão das concepções de ser humano, da natureza, da sociedade, de conhecimento, da educação, do ensino e da aprendizagem, das pretensões sobre a escola e seu papel social, das práticas pedagógicas e das relações nela vividas. E, como resultado disso, a seleção intencional de conhecimentos pelos quais devem ser socializados para toda a população, uma vez que são requisitos fundamentais para o processo de humanização de cada indivíduo (MALANCHEN, 2014, p. 05).

O currículo como um produto histórico, resultante de uma luta coletiva, de uma disputa entre classes antagônicas que envolve aspectos ideológicos, políticos e pedagógicos (ORSO; MALANCHEN, 2016, p. 03) deve estar alinhado com o interesse da classe trabalhadora, portanto, deve explicitar as lutas de classe na qual vivemos na sociedade capitalista.

Um currículo para a educação no campo, que visa a preparação do educando para compreender e atuar criticamente na sociedade, visa a superação da visão idealista (aquela que obscurece as lutas contraditórias contidas na sociedade capitalista), para que se possa situá-lo no mundo materialista, histórico e dialético.

Aqui reside a importância de um currículo que valorize a transmissão do conhecimento sistematizado em suas formas mais elaboradas para a formação humana em prol do desenvolvimento da consciência crítica e formação do sujeito autônomo. Para tanto, é necessária uma organização curricular que tome como parâmetro a forma de organização do trabalho da sociedade atual, com todas as suas contradições, colocando como exigência um acervo mínimo de conhecimentos sistemáticos, assegurando

\footnotetext{
3 Destaque feito pelo próprio autor.
} 
sua plena compreensão por parte de todos os educandos, de forma que possam participar ativamente da vida da sociedade (SAVIANI, 2016b).

Na perspectiva materialista histórica e dialética, a atividade de ensino não silencia a realidade concreta, não "separa o conhecimento sobre o mundo (dimensão epistemológica) da existência efetiva deste próprio mundo (dimensão ontológica), vistas as relações entre os conteúdos escolares e a totalidade da atividade humana historicamente desenvolvida" (LAVOURA; MARTINS, 2017, p. 535), tendo em vista a formação de um ser omnilateral, livre e universal (DUARTE, 2013).

Desse modo, o currículo tem esta característica, imprescindível, que é a formação humana, com base nos conhecimentos científicos, filosóficos e artísticos, pois tal base é a forma de superação do senso comum pelo conhecimento elaborado - sendo esse o papel da escola. Daí a importância do desenvolvimento de um currículo para as escolas com classes multisseriadas de forma a favorecer a aprendizagem mediada por conteúdos que possibilitem a ascensão do pensamento cotidiano, do sensível ao elaborado, pautados no conhecimento que possibilite a compreensão das relações sociais, "constituídas histórica e dialeticamente, entre conhecimentos, concepções de mundo e prática social" (DUARTE, 2015, p. 10).

O ato de conhecer a partir da prática social, vai além da aparência, posto que a melhor forma de conhecer o objeto de estudo é "começar pelo real e pelo concreto, que são a condição prévia e efetiva" (MARX, 2003, p. 47), o que "implica não apenas deter informações caóticas e precárias dessa prática social, mas também compreendê-la como síntese de múltiplas relações e determinações numerosas" (LAVOURA; MARTINS, 2017, p. 534).

O currículo para as classes multisseriadas, bem como para todas as outras, constitui um conjunto de atividades política e pedagógica desenvolvidas na escola, mediadas pela prática social, tendo o papel de proporcionar a compreensão da sociedade em seu movimento e à formação integral do indivíduo, promovendo o "desenvolvimento das capacidades humanas complexas, das operações lógicas do raciocínio, dos 
sentimentos éticos e estéticos, da autonomia da conduta" (MARTINS, 2013, p. 135).

\section{ORGANIZAÇÃO CURRICULAR DAS SALAS MULTISSERIADAS E A PEDAGOGIA HISTÓRICO-CRÍTICA}

Nos últimos anos as salas multisseriadas têm tido certa visibilidade no meio acadêmico e nas políticas públicas. Em um país com tanta diversidade geográfica estas salas configuram uma realidade comum, especialmente nas regiões Norte e Nordeste, de maior dimensão territorial e ocupação humana dispersa, mas, não se resumem a essas localidades, sendo encontradas em todas as regiões do país. Esse fato por si só nos impele a pensar e discutir sobre a organização curricular da classe multisseriada, cuja configuração básica é o agrupamento de alunos com idades, ritmos de aprendizagem e anos (série) de escolaridade diferentes, sob a regência de um único professor. No Brasil, há, de acordo com o Censo Escolar de 2019, 55.300 mil escolas rurais, das quais $48,6 \%$ são de pequeno porte com até 50 alunos (BRASIL, 2020). São nessas escolas, com quantidade menor de alunos que prioritariamente se organizam por multissérie.

Embora a predominância da multissérie nas escolas rurais, nem todas as escolas no meio rural são multisseriadas e unidocentes. Também se pode encontrar outro tipo de organização em virtude do número de alunos como, por exemplo, numa mesma escola pode coexistir turmas/classes seriadas, organizadas pelos anos de ensino, neste caso, não sendo unidocentes (JACOMELI; CARDOSO, 2011). Além disso, ainda pode-se encontrar a junção de dois níveis de ensino, exemplo, pré-escola com o ensino fundamental, passando a ser denominada de multietapa e multisseriada.

A escola multisseriada torna-se importante para os trabalhadores do campo e seus filhos, pois na maioria das vezes é a única instituição estatal que Ihes chega e, de alguma forma, é a garantia do direito público subjetivo de qualquer cidadão de ser atendido nas suas necessidades de formação educacional obrigatória, como está estabelecido nos pressupostos legais e nas políticas educacionais brasileiras. 
Por outro lado, no imaginário social há uma histórica visão negativa que liga essas escolas ao atraso e à má qualidade de ensino ofertado, como diz Arroyo (2010, p. 10) no Prefácio do livro 'Escola de Direito: reinventando a escola multisseriada',

\begin{abstract}
Predominam imaginários extremamente negativos a ser desconstruídos: a escola multisseriada pensada na pré-história de nosso sistema escolar; vista como distante do paradigma curricular moderno, urbano, seriado; vista como distante do padrão de qualidade pelos resultados nas avaliações, pela baixa qualificação dos professores, pela falta de condições materiais e didáticas, pela complexidade do exercício da docência em classes multisseriadas, pelo atraso da formação escolar do sujeito do campo em comparação com aquele da cidade...
\end{abstract}

Esse imaginário expressa não somente uma visão negativa da escola no meio rural, mas, do povo que vive no campo e de suas instituições e, "essas imagens tão negativas do campo e de suas escolas tiveram e têm uma intencionalidade política perversa: reduzir o campo, suas formas de existência e de produção de seus povos à inexistência" (ARROYO, 2010, p. 10).

A escola da zona rural quando oposta à escola da zona urbana reproduz uma falsa oposição, uma falsa dicotomia, mas que é muito perigosa para a manutenção dessas escolas no meio rural, pois justifica a sua extinção, o seu fechamento, as nucleações, que por sua vez resultam nas políticas de transporte escolar retirando os estudantes de seu lugar de morada para transportá-lo a uma escola distante, enfrentando todos os riscos que aparecem nesse percurso, além da distância entre a sua casa e a escola. Ainda de acordo com Arroyo (2010, p. 10-11), a escola assim, é considerada como não Escola,

terra de direito educandário, sem qualidade; os educadoresdocentes, como não educadores, não docentes; a organização curricular não seriada, multisseriada, como inexistente; os diversos povos do campo, na pré-história, na inferioridade cultural. Em contraposição, a cidade, assim como a escola, os currículos seriados, seus docentes e sua qualidade, são existentes. Padrões de referência e paradigmas de modernidade, cientificidade, conhecimento, produtividade, que têm classificado, hierarquizado nossas escolas, docentes e coletivos que as frequentam. 
Entretanto, afirma o autor, esse imaginário deve ser alterado, pois "as escolas multisseriadas merecem outros olhares". Enquanto o olhar sobre essas instituições for pautado por essas dicotomias campo x cidade, rural x urbano, seriado $\mathrm{x}$ multisseriado as interpretações seguirão viciadas, preconceituosas, excludentes, hierarquizantes, inferiorizantes, segregadoras. É necessário mudar a visão que se tem sobre essas escolas e seus usuários.

Vale ressaltar que essas escolas por via de regra constituem a única alternativa de os filhos desses trabalhadores terem acesso ao conhecimento sistematizado, o que indica a sua importância e, portanto, precisam ser reconhecidas, respeitadas, melhor amparadas e organizadas pelo poder público para que consigam se reinventar e não mais sejam ignoradas e relegadas a segunda categoria, como têm sido.

É oportuno destacar que a multissérie permite $O$ encontro e convivência de alunos de diversas idades e turmas distintas, o que torna não um problema, mas um ponto positivo para o desenvolvimento das crianças, pois na heterogeneidade se pode enriquecer um currículo, focando a troca entre os pares. Tal pressuposto, é explicado por Marsiglia e Martins (2014) quando falam sobre a apropriação da cultura. Para estas autoras, a internalização da cultura se estabelece primeiro nas relações interpessoais, na mediação com os outros indivíduos, pois toda função psíquica é primeiramente interpessoal, para depois se tornar intrapessoal.

De acordo com Martinic (2015), os espaços educativos mais diversos potencializam o processo de aprendizagem, não somente no manejo dos conteúdos do currículo, mas também quanto à integração dos alunos. Como estão em idades diferentes, os estudantes mais novos buscam integração com os mais velhos, a colaboração e o entendimento entre eles são mútuos, os mais novos têm a oportunidade de escutar estratégias mais avançadas de aprendizagem. O espírito de cooperação surgido do trabalho em equipe leva essas crianças a terem menos conflitos intergrupais e intragrupos, o que dá como resultado menos desacordos e brigas e mais respeito pelo coletivo. 
Vale destacar, que não estamos aqui dizendo que este é o modelo mais apropriado para as escolas no campo, e nem tão pouco estamos afirmando que o modelo seriado seja, mas aqui reside a defesa de uma organização do ensino que privilegie a aprendizagem dos alunos, e, para tanto, é necessária uma prática pedagógica que eleve a formação intelectual de todos.

Como ponto de partida para se pensar na organização curricular para as salas multisseriadas está a abolição da seriação no momento de realizar o planejamento e na sua execução. O trabalho com as classes multisseriadas não pode ser via seriação (dividida em anos escolares), um plano de aula para cada ano, pois o professor teria que ter 2, 3, 4 ou 5 planos para serem desenvolvidos na sala de aula, como via de regra fazem os professores no planejamento anual e diário. Essa estratégia didática é ineficiente, pois é difícil acompanhar os trabalhos que estão sendo desenvolvidos por todos os alunos, individualmente e por ano, e geralmente acaba-se por priorizar as crianças menores, que ainda estão no processo de alfabetização em detrimento dos outros que podem não receber o devido acompanhamento e intervenção para a construção do conhecimento (NUNES; BEZERRA, 2018).

Portanto, cabe repensar a organização escolar multisseriada a partir de sua realidade concreta, que é a presença de alunos de idades e anos de escolaridade diferentes na mesma sala. Começando pelo planejamento, tanto anual quanto o diário e ou semanal.

Embora seja necessário repensar essa organização escolar, o professor permanece como aquele que já se apropriou dos elementos culturais humanizadores e que organiza o trabalho pedagógico, considerando aquilo que já foi apropriado pelo aluno e almejado no processo de ensino e aprendizagem (MARSIGLIA; MARTINS, 2014). Exige a superação da prática automática e pragmática de planejamento escolar, elaborado apenas para cumprir a burocracia escolar, resultando em uma sequência de conteúdo, procedimentos e recursos didáticos distribuídos ao longo do tempo. Esse modelo de planejamento é externo ao professor, passível de ser esquecido, ao se tornar ato mecânico e que geralmente não reflete os anseios e 
necessidades formativas da turma, não no sentido de adequação de conteúdos ao cotidiano imediato alienado, mas no sentido do entendimento dos avanços na aquisição do conhecimento por parte dos alunos, do aprofundamento dos estudos e das fases do desenvolvimento infantil.

De acordo com Marsiglia e Martins (2014, p. 182) "planejar é também desejar, é unidade afetivo cognitiva, resultante do desenvolvimento de propriedades ontológicas essenciais dos seres humanos [...]" um exercício e expressão do pensamento teórico, das operações lógicas do raciocínio, representada por análises, sínteses, generalizações e abstrações.

As autoras destacam que o planejamento do ensino contempla dois planos: vertical e horizontal. O plano vertical contempla a identificação e seleção daquilo que vai ser ensinado a médio e longo prazo, refere-se à seleção dos conteúdos para um tempo mais prolongado, para a etapa, o ciclo, o ano, o conjunto de séries. O plano horizontal é um desdobramento do plano vertical. É aquele que vai especificar, aprofundar e particularizar os conteúdos elencados para o período mais longo (do plano vertical) e transformá-lo em conteúdo de ensino a curto prazo, mensal, semanal, diário, a partir da identificação dos conhecimentos conquistados e os que ainda precisam ser conquistados (MARSIGLIA; MARTINS, 2014).

Entre uma e outra dimensão do planejamento - do planejamento global ao diário - deve-se almejar que o "percurso do ensino, aquele que deve estar sob o domínio do professor, não reproduza a 'lógica infantil', ocorrendo, pois, de 'cima para baixo', do geral para o particular, do abstrato ao concreto" (MARSIGLIA; MARTINS, 2014, p. 183). De acordo com as autoras, o cotidiano, o sensorial, o concreto estão presentes, porém como ponto de intersecção entre a aprendizagem, ou seja, o aluno e o ensino, na figura do professor e, são taxativas: "apenas assim podem corroborar para a superação dos domínios cotidianos em direção aos conhecimentos mais elaborados" (idem).

Ultrapassar um planejamento seriado supõe considerar que as turmas podem ser organizadas de maneira diferente, como expresso na Lei de 
Diretrizes e Bases da Educação Nacional (BRASIL, 2020) em seu artigo 28 que trata da oferta de educação básica para a população rural, que os sistemas de ensino promoverão as adaptações necessárias à sua adequação, às peculiaridades da vida rural e de cada região, no que tange aos

I- conteúdos curriculares e metodologias apropriadas às reais necessidades e interesses dos alunos da zona rural;

II - organização escolar própria, incluindo adequação do calendário escolar às fases do ciclo agrícola e às condições climáticas;

III - adequação à natureza do trabalho na zona rural.

A legislação de ensino brasileira possibilita a adequação da organização do ensino nas escolas rurais de acordo com as especificidades que thes são características: tempo, espaço e natureza do trabalho. Assim, essas escolas contam com uma autonomia delegada pela própria LDB e podem buscar formas alternativas de garantir a efetividade do trabalho educativo de forma que possibilite conduzir os alunos do conhecimento sensível, imediato, cotidiano, espontâneo ao conhecimento historicamente produzido e sistematizado via conteúdo escolar.

Para uma sala multisseriada pode-se elaborar um planejamento único para a turma, de acordo com os conteúdos planejados para cada etapa, com a distribuição das tarefas conforme a complexidade do conhecimento e aprofundamento teórico e prático, levando em consideração a adequação a cada nível de desenvolvimento psíquico. No entanto, a Base Nacional Comum Curricular - BNCC (2017) determina competências específicas por área de conhecimento, no caso em tela, para o Ensino Fundamental, que vão se articular horizontalmente e verticalmente entre a primeira fase do ensino fundamental e a segunda fase. Cada componente curricular apresenta um conjunto de habilidades que se relacionam com o objetivo do conhecimento (conteúdo, conceitos e processos) organizados em unidades temáticas, o que sugere um trabalho interdisciplinar.

Embora a 'Base' seja o documento curricular norteador do ensino brasileiro, e, portanto, em última instância, daquilo que acontece nas salas multisseriadas, nunca é demais ressaltar que a BNCC é uma proposta reformista ancorada na égide neoliberal, que tem seus pressupostos 
definidos a partir da visão empresarial, se estrutura por competências e habilidades, altamente instrumentalista e que tem por objetivo controlar o que crianças e jovens vão aprender e como vão aprender, além de controlar o trabalho docente, através das avaliações externas, se colocando a serviço do avanço político e ideológico da classe dominante da direita e extrema direita.

Dito isto, convém retomar as análises de Marise Ramos (2006) que demonstra o caráter individualista do termo competência, definido por ela como a conjugação dos diversos saberes mobilizados pelo indivíduo (saber, saber-fazer e saber-ser) na realização de uma atividade. Assim, pode-se inferir que competência é a capacidade do sujeito desenvolver diferentes saberes, atitudes e valores por meio dos conhecimentos e da vivência construída na escola.

Portanto, o princípio fundante da BNCC, é formar sujeitos a partir do conhecimento atitudinal, esvaziado da compreensão de uma totalidade maior da qual este sujeito faz parte. Estes conhecimentos mobilizados na forma de competência estão ligados aos quatro pilares da educação proposto pela UNESCO, a saber: aprender a conhecer, aprender a fazer, aprender a conviver e aprender a ser (DELORS, 1998), que constituem o arcabouço teórico das pedagogias do aprender a aprender.

De modo geral, esses fundamentos alimentam a noção de que competência pode promover o encontro entre formação geral e emprego, visto que os alunos deverão dominar conhecimentos considerados importantes para o mundo do trabalho, cada vez mais competitivo. Observa-se que a lista de habilidades é prescrita para atender o imediatismo, a indústria cultural, pela via mercadológica que está sendo proposta mais acirradamente na atual conjuntura política. Tal proposta, recai no esvaziamento dos conteúdos importantes para a formação humana, provocando uma semiformação de crianças e jovens, sem reflexão e criticidade, tornando-se presas fáceis para o sistema.

Por outro lado, se ainda prevalecesse a autonomia que a LDB $n^{\circ}$ 9.394/96 delega, as escolas poderiam elaborar um currículo que distribua $\circ$ 
conhecimento a ser adquirido pelo aluno ao longo da fase de escolarização, que pode contemplar ciclos ou etapas $\left(1^{\circ}\right.$ ao $3^{\circ}$ ano; $4^{\circ}$ e $5^{\circ}$ anos), ou, ao longo dos 5 anos, dosando de acordo com o nível de desenvolvimento de cada aluno. Neste sentido, os professores precisam ir além do que está prescrito na BNNC, isso evitaria alguns problemas que são frequentes nas salas multisseriadas: o professor divide a sala em anos de escolaridade, explica o conteúdo do dia para cada "furma" ou "série", uma de cada vez, de modo que a criança que está no quarto ou quinto ano, escuta o que o professor explica para uma turma, depois à outra e à outra até chegar a dele. Um planejamento único para todas as "séries" possibilitaria ganho de tempo para a criança e acesso a conhecimento menos fragmentado e mais significativo. Mas infelizmente, com a atual estrutura da base, articulada com as avaliações externas, isso fica cada vez mais difícil, mas não impossível, pois no campo de disputa, há resistência, contradição e o protagonismo do professor.

A forma de organização das turmas é fundamental. O grupo é a forma mais adequada, pois "demanda organização interna, encerram possibilidades e limites, direitos e deveres, enfim, uma dinâmica de funcionamento coordenada" (MARSIGLIA; MARTINS, 2014, p. 185) de pessoas que se articulam e se organizam em torno de um objetivo comum. Cabe ao professor a liderança, a coordenação dos trabalhos em virtude de toda a sua formação, seu preparo e suas capacidades.

A ênfase e o avanço na aquisição e ampliação dos conhecimentos dos alunos se dará pelas intervenções que o professor fará com cada ano e nível de desenvolvimento do aluno, para que possa ocorrer a aprendizagem. Para isso, faz-se necessária uma organização da sala de aula, que requer trabalho com o grupo de alunos heterogêneos no nível de aquisição do conhecimento.

As salas de aula geralmente são organizadas de acordo com uma ideia de homogeneidade: alunos de 07 anos, 08 anos e assim, sucessivamente, partindo-se do princípio que a idade corresponde a um patamar de desenvolvimento biológico e maturacional que conduz a todos 
ao mesmo nível de aprendizagem. Isso garantiria que todos ingressassem do mesmo ponto e que, chegariam a um outro ponto, juntos. Entretanto, "não é a idade da criança que determina o conteúdo do estágio do desenvolvimento, os próprios limites de idade de um estágio, pelo contrário, dependem de seu conteúdo e se alteram pari passu com a mudança das condições histórico-sociais" (LEONTIEV apud PASQUALINI, 2011, p. 66).

O desenvolvimento infantil é um fenômeno histórico e dialético, não é determinado por leis naturais universais, mas, está ligado às condições objetivas da organização social e não se desenrola de forma linear, progressiva e evolutiva, mas, compreende saltos qualitativos, involuções e rupturas (PASQUALINI, 2011, p. 66). Ressalta-se mais uma vez o papel diretivo do trabalho do professor na promoção do desenvolvimento da criança.

Existem formas diferentes de organização das aulas na multissérie. Na dinâmica das aulas, existirão momentos de compartilhamento geral, de aproximação entre todos os seus membros, grupo sala e momentos de compartilhamento específico, em subgrupos ou grupos-séries, a partir dos quais resulta uma terceira forma de compartilhamento: entre indivíduos de diferentes séries (MARSIGLIA; MARTINS, 2014, p. 186).

De acordo com as autoras, deve-se promover esses três tipos de grupalização:

entre todos os alunos da sala, independentemente das séries a que pertençam (por exemplo, uma visita de estudos), entre alunos de uma mesma série (a exemplo de um trabalho em duplas ou trios) e entre alunos de diferentes séries la exemplo de duplas ou trios formados para resolver um dado um 'desafio' em relação aos conteúdos ensinados) (MARSIGLIA; MARTINS, 2014, p 186).

Essa relação entre pares, a colaboração, o intercâmbio entre alunos mais e menos experientes, sem excluir a necessária intervenção do professor na transmissão dos conhecimentos potencializa o papel educativo que podem ter as relações entre pares com diferentes graus e tipos de aprendizagens (MARSIGLIA; MARTINS, 2014, p. 188). De acordo com as autoras, "favorece aos envolvidos novas e ricas formas de sedimentação dos mesmos, resultantes do complexo interacional criança-criança" (idem). 
Tomando por base o planejamento vertical, o aluno pode ser agrupado de acordo com seus avanços na aprendizagem e em busca de superação de suas dificuldades, de forma que ele pode estar agrupado com colegas diferentes em diferentes partes do dia e dias da semana. Se ele está matriculado no quarto ano e ainda não atingiu a base alfabética, pode ser agrupado com aqueles alunos que estão se dedicando a essa tarefa. Se não domina os princípios das operações formais, em outro momento estará em um grupo que esteja focado na resolução de problemas ou desenvolvendo as bases matemáticas. Para atingir esse nível de organização, há a necessidade de períodos sistemáticos de avaliação, planejamento e replanejamento coletivo periódico e o envolvimento de toda equipe pedagógica. Dessa forma se prioriza a aprendizagem do aluno em detrimento de padrões sedimentados de organização escolar pautada na idade e ou série: pauta-se pela aprendizagem dos alunos, ou seja, pela aquisição dos conhecimentos sistematizados.

Disso decorre a importância de se conhecer o nível de desenvolvimento dos alunos para que se possam organizar os grupos de estudo na sala de aula para que todos possam aprender, sob a orientação do professor. Assim, permitir que o pensamento chegue à síntese das múltiplas determinações de uma totalidade concreta, pois um bom planejamento e condução do processo educativo requer uma ação pedagógica que se integre à realidade concreta, em busca da transformação da realidade social.

Importa salientar que não haverá avanço significativo no atendimento pedagógico se continuar com este tipo de prática, e, ainda, sem a "superação de práticas pedagógicas assistemáticas e de uma concepção de planejamento pedagógico que, equivocadamente, o toma (somente) como sinônimo de organização da rotina institucional" (MARTINS; MARSIGLIA, 2015, p.16). Além disso, deve-se ter objetivos claros a atingir, ou seja, saber onde se quer chegar e o que fazer para chegar; o planejamento pedagógico não pode ser tomado como procedimento em si mesmo, esvaziado de conhecimento sobre a especificidade do desenvolvimento 
humano e do papel que a escola desempenha nele. Deste modo o professor deve, ao planejar suas aulas e colocá-las em prática, pensar o ponto de partida e o ponto de chegada mediados pela prática social. De acordo com Lavoura e Martins (2017, p. 538),

Compreender o trabalho educativo como atividade humana exige que pensemos a sua organização a partir da delimitação do objeto do ensino e da aprendizagem - correspondentes aos conhecimentos sistematizados dos fenômenos da realidade objetiva e convertidos em conteúdos escolares -; qual a sua finalidade definidora dos objetivos do ato educativo que, ao coincidirem com o objeto da atividade (os conteúdos escolares), promovem os motivos do ensino e da aprendizagem; $e$ as formas pelas quais $o$ ensino e a aprendizagem se realizam, visando explicitar quais ações e operações (procedimentos de ensino) devem ser realizadas por professores e alunos diante das tarefas escolares que pretendem concretizar $o$ processo de transmissão e apropriação do conhecimento.

Isto posto, "o planejamento de ensino deve contemplar as experiências que mais corroborem para a formação de conceitos por parte dos alunos" (MARSIGLIA; MARTINS, 2014, p. 189), devendo contemplar tanto questões que envolvem situações gerais como as específicas da prática social.

Pensando a educação no campo, cabe ao professor compreender e problematizar a "essencialidade da terra para a vida humana" (SAVIANI, 2016a, p. 25), a relação campo e cidade, a histórica concentração de terra no Brasil, e aqui se insere a questão da reforma agrária, a migração do trabalhador rural para outras cidades e região do Brasil, a produção dos insumos agroindustriais, o uso do agrotóxico, as questões ambientais (SAVIANI, 2016a), acrescentemos ainda, discussões que envolvem a economia solidária, as diferentes formas de expropriação e exploração do trabalho no campo, agricultura familiar, sustentabilidade, entre outros.

Conforme foi exposto,

este é o quadro em que se desenvolve a prática social do morador do campo. Na perspectiva da pedagogia histórico-crítica, o professor precisa ter clareza desse quadro já no ponto de partida, pois essa é uma condição para que ele possa concorrer, pelo trabalho educativo, para que os alunos ascendam a essa compreensão no ponto de chegada (SAVIANI, 2016a, p. 35-36). 
Desse modo, o professor deve, ao planejar suas aulas e colocá-las em

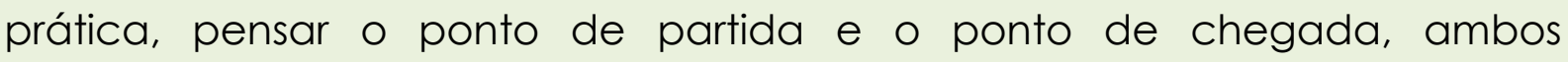
movimentos imbricados e mediados pela prática pedagógica, considerando o contexto em que vivem os alunos do campo, mas fazendo relação com o contexto geral, a sociedade capitalista. "Para tanto, o corpo de conhecimentos deve ser estruturado em espiral crescente, quando a proposição de conteúdos mais complexos é gerada a partir de formulações e compreensões já garantidas" (MARSIGLIA; MARTINS, 2014, p. 189), como é o caso do ponto de partida da prática social inicial, que parte da realidade que o aluno vive.

Para tanto, deve-se atentar para a seleção dos conteúdos a serem trabalhados, levando em consideração o que é essencial para a aprendizagem dos alunos, o nuclear, deixando para o segundo plano 0 secundário, o que não é prioridade, lembrando Saviani (2016b). Neste sentido, o eixo, como elemento central, articulará os princípios, nexos e as relações que os conteúdos fazem entre eles, e, ainda, determinará as abordagens introdutórias e de aprofundamento dos conteúdos, ajudando os alunos a caminharem do abstrato para o concreto.

Este percurso aqui proposto, seria a base para a proposta curricular das escolas multisseriadas, tendo os eixos integradores como ponto de partida, os professores das escolas no campo poderão selecionar e organizar os conteúdos escolares de forma a promover o percurso da síncrese à síntese, por via da mediação pedagógica. A partir da prática social, não se retorna da mesma forma que quando do ponto de partida, mas incorporada a um elemento adicional e enriquecedor, dentro de um contexto da prática social global, no movimento dialético (LAVOURA; MARTINS, 2017).

Esta mudança do modo de ensinar exigiria o desenvolvimento de uma proposta pedagógica que contemple a organização da multisseriada, priorizando o planejamento coletivo e democratização do acesso ao conhecimento sistematizado. 
Vê-se, o que está sendo proposto, é a ruptura com uma escola classista, ou seja, determinada escola para determinada classe da sociedade em detrimento de outra, seria necessário banir este tipo de escola e criar uma escola única, para todos, que integrasse duas dimensões, a formativo-humanística com a prático-produtiva, o que não significaria a escola nivelar por baixo a educação ofertada, pelo contrário, deveria oferecer todo rigor, complexidade dos conteúdos e os saberes acumulados pela humanidade. Ou melhor dizendo, deve-se formar o jovem como "pessoa capaz de pensar, de estudar, de dirigir ou de controlar quem dirige" (GRAMSCl, 1989, p. 136).

\section{CONCLUSÕES}

A escola multisseriada é uma forma de organização escolar predominante nas áreas rurais. Essas escolas muitas vezes são compostas de uma ou duas salas de aula, que atendem alunos de diferentes idades e séries aos cuidados de um único professor. Esse modelo de escola tem sobrevivido ao longo do tempo, é carregada de um ideário negativo que a coloca em uma posição de subalternidade diante das escolas urbanas, alimentada por falsas dicotomias que ocultam a realidade concreta do campo no Brasil, com seus conflitos e desigualdade histórica, fruto do desenvolvimento desigual do capitalismo no campo. Essa imagem negativa escamoteia a visão, também negativa, que se tem do homem do campo, que é relegado ao esquecimento e apagamento de suas lutas históricas, considerado cidadão de segunda categoria para quem qualquer escola serve.

Nos últimos anos, o movimento social - de luta pela terra e de luta pela educação do campo - retirou a escola rural do ostracismo a que estava relegada e a erigiu a objeto de debates/embates políticos, de conquistas de políticas públicas educacionais e de fortalecimento das instituições escolares do campo. A escola passou a ser vista, inclusive pela academia. Tem crescido os estudos e pesquisas, eventos e publicações abordando a escola 
multisseriada, as salas multisseriadas e os processos educativos que acontecem em seu interior.

Neste texto buscamos entrar nessa seara e nos detivemos sobre o ensino nas escolas e salas multisseriadas, a partir da perspectiva da Pedagogia Histórico-Crítica, para a qual a educação escolar tem um papel fundamental no processo de humanização do homem. A educação escolar está diretamente relacionada com a transmissão do saber sistematizado, do conhecimento e a escola é a instituição responsável pela socialização dos elementos culturais, produzidos historicamente pela humanidade e que por meio do trabalho educativo escolar, são repassados para as novas gerações.

Esses conteúdos estão expressos no currículo, que é um documento que registra as atividades nucleares que são desenvolvidas pela escola, portanto, tem a ver com a seleção dos conhecimentos historicamente produzido pelos homens e transformados em conteúdos escolares e a identificação da melhor forma de transmissão desses. O currículo para as classes multisseriadas, bem como para todas as outras deve levar a compreensão da sociedade em seu movimento e à formação do indivíduo, com base nos conhecimentos científicos, filosóficos e artísticos, pois tal base é a forma de superação do senso comum pelo conhecimento elaborado.

Enquanto identificação da melhor forma de realizar essa tarefa, as escolas/turmas/classes multisseriadas, para ser mais efetiva em sua função de ensino, para enfrentar e romper com as visões negativistas, pode ser vista como potencialidade, trazendo possibilidades de organização escolar que em muito pode colaborar com as escolas urbanas, que se organizam sob o manto sagrado da seriação e da pseudo-homogeneidade.

As escolas multisseriadas podem avançar no sentido de apontar novas formas de planejamento das atividades pedagógicas. Para uma sala multisseriada pode-se elaborar um planejamento único para a turma, de acordo com os conteúdos planejados para cada etapa, com a distribuição das tarefas de acordo com a complexidade do conhecimento e adequação a cada nível de desenvolvimento psíquico. Pode passar pela 
eliminação das séries e se pautar nos níveis de aprendizagem dos alunos, garantindo dessa maneira o acesso ao conhecimento, sem que nenhum aluno fique para trás.

Nesse sentido, reafirmamos a importância da escola no campo, com todas as suas formas de organização, especialmente, a multisseriada, que se encontra constantemente sob ameaça de fechamento. Portanto, a educação é um instrumento de luta, e, se, de fato, o acesso a escolaridade e a aprendizagem por meio da aquisição dos conteúdos escolares estivesse garantido, não estaríamos discutindo um tipo adequado de organização escolar. A escola no meio rural existe, sendo ela multisseriada ou não, tendo salas multisseriadas unidocentes ou não. Cabe-nos tirar essa instituição do ostracismo, do apagamento e valorizar os profissionais que fazem com que ela sobreviva, apesar dos ataques, do desmonte das políticas educacionais e, refletir, dialogar, construir, juntamente com esses professores e demais trabalhadores da educação, metodologias de ensino mais adequadas à realidade das salas multisseriadas, tomando como base uma teoria pedagógica sólida, que promova o desenvolvimento omnilateral do sujeito e contribua para o seu desenvolvimento individual e social.

\section{REFERÊNCIAS}

ARROYO, M. G. Prefácio. In: ROCHA, M. I. A.; HAGE, S. M. (Org.). Reinventando a escola multisseriada. Belo Horizonte: Autêntica, 2010.

BRASIL. Lei de Diretrizes e Bases da Educação. Lei no 9.394/1996. Disponível em: https://www.planalto.gov.br/ccivil_03/Leis/L9394.htm. Acesso em: 28 de abr. de 2020.

BRASIL. Base Nacional Comum Curricular: educação é a base. Linguagens, educação física, ensino fundamental, 2017. Disponível em:

http://basenacionalcomum.mec.gov.br/images/BNCC_publicacao.pdf. Acesso em: 11 de abr. de 2019.

BRASIL. Instituto Nacional de Estudos e Pesquisas Educacionais Anísio Teixeira (Inep). Censo da Educação Básica 2019: notas estatísticas. Brasilia, 2020.

BRASIL. Base Nacional Comum Curricular. Brasília: MEC/CNE/2017. Disponível em: $<\mathrm{http}$ ://basenacionalcomum.mec.gov.br/images/BNCC_El_EF_110518_versaofinal_si te.pdf>. Acesso em: 18 de abr. 2021. 
DELORS, J. et al. Educação um tesouro a descobrir: relatório para a UNESCO da Comissão Internacional sobre Educação para o século XXI. Brasília: DF, MEC, UNESCO, 1998.

DUARTE, N. A Individualidade Para Si. Contribuição a uma teoria histórico-crítica da formação do indivíduo. Edição Comemorativa. Campinas, SP: Autores Associados, 2013.

GRAMSCl, A. Os intelectuais e a organização da cultura. Rio de Janeiro: Civilização Brasileira, 1989.

HAGE, S. A. M. A. Multissérie em pauta: para transgredir o Paradigma Seriado nas Escolas do Campo. 2008. Disponível em:

<www.faced.ufba.br/sites/faced.ufba.br/files/multisserie_pauta_salomao_hage.pdf> . Acesso em: 18 de abr. 2017.

HAGE, S. A. M. A. Transgressão do paradigma da (multi)seriação como referência para a construção da escola pública do Campo. Revista Educação e Sociedade, Campinas, v. 35, n. 129, p. 1165-1182, 2014. Disponível em:

<www.scielo.br/pdf/es/v35n129/0101-7330-es-35-129-01 165.pdf>. Acesso em: 18 de abr. 2017.

JACOMELI, M. R. M.; CARDOSO, M. A. O Programa Escola Ativa e a gestão democrática: análises e possibilidades. In: BEZERRA NETO, L.; BEZERRA, M. C. dos S. (Orgs.). Educação para o campo em discussão: reflexões sobre o programa escola ativa. São José: Premier, 2011.

LAVOURA, T. N.; MARTINS, L. M. A dialética do ensino e da aprendizagem na atividade pedagógica histórico-crítica. Interface (Botucatu), Botucatu, v. 21, n. 62, p. 531-541, 2017. Disponível em: <http://www.scielo.br/pdf/icse/2017nahead/18075762-icse-1807-576220160917>. Acesso em: 13 fev. 2018.

MARSIGLIA, A. C. G.; MARTINS, L. M. Contribuições gerais para o trabalho pedagógico em salas multisseriadas. Revista Nuances: estudos sobre Educação, Presidente Prudente-SP, v. 25, n. 1, p. 176-192, jan./abr. 2014.

MARTINIC, S. El tiempo y el aprendizaje escolar la experiencia de la extensión de la jornada escolar en Chile. Revista Brasileira de Educação, v. 20, n. 61, p. 479-499, abr./jun. 2015. Disponível em: http://www.scielo.br/pdf/rbedu/v20n61/1413-2478rbedu-20-61-0479.pdf. Acesso em: 24 de abr. de 2020.

MARTINS, L. M. Os fundamentos psicológicos da pedagogia histórico-crítica e os fundamentos pedagógicos da psicologia histórico-cultural. Revista Germinal: Marxismo e Educação em Debate, Salvador, v. 5, n. 2, p. 130-143, dez. 2013.

MALANCHEN, J. Currículo e Pedagogia Histórico-Crítica: a defesa da universalidade dos conteúdos escolares. X ANPED Sul. Florianópolis, outubro de 2014. Disponível em: http://xanpedsul.faed.udesc.br/arq_pdf/597-0.pdf. Acesso em: 27 de abr. de 2020.

NUNES, K. de C. S.; BEZERRA, M. C. S. Escolas multisseriadas rurais no estado do Tocantins e pedagogia histórico-crítica: aproximações. Rev. HISTEDBR On-line, Campinas, v.18, n.1 [75], p.258-275, jan./mar. 2018. 
ORSO, P. J.; MALANCHEN, J. Pedagogia histórico-crítica e a defesa do saber objetivo como centro do currículo escolar. In: X Seminário Nacional do HISTEDBR. 30 anos do Histedbr (1986-2016) - Contribuições para a História e Historiografia da Educação Brasileira. 2016. Disponível em:

https://www.fe.unicamp.br/eventos/histedbr2016/anais/pdf/881-2719-1-pb.pdf. Acesso em: 28 de abr. de 2020.

PARENTE, C. da M. D. Escolas Multisseriadas: a experiência internacional e reflexões para o caso brasileiro. Ensaio: aval. pol. públ. Educ., v.22, n. 82, p. 57-88, jan./mar. 2014. Fundação Cesgranrio: Rio de Janeiro, Brasil.

PASQUALINI, J. C. A educação escolar da criança pequena na perspectiva histórico-cultural e histórico-crítica. In: MARSIGLIA, A. C. G. (Org.). Pedagogia histórico-crítica: 30 anos. Campinas-SP: Autores Associados, 2011 , p. 59-89.

RAMOS, M. N. A pedagogia das competências: autonomia ou adaptação? $3^{a}$ ed. São Paulo: Cortez, 2006.

SAVIANI, D. Pedagogia histórico-crítica: primeiras aproximações. $11^{a}$ ed. rev. Campinas, SP: Autores Associados, 2011.137 p. (Coleção educação contemporânea).

SAVIANI, D. Trabalho e Educação: fundamentos ontológicos e históricos. Revista Brasileira de Educação, v. 12, n. 34, jan./abr., 2007b. Disponível em:

http://www.scielo.br/pdf/rbedu/v12n34/a12v1234.pdf. Acesso em: 27 ago. 2018.

SAVIANI, D. A pedagogia histórico-crítica na educação do campo. In: BASSO, J. D.; SANTOS NETO, J. L.; BEZERRA, M. C. dos S. (Org.). Pedagogia histórico-crítica e educação no campo: história, desafios e perspectivas atuais. São Carlos: Pedro e João Editores e Navegando, 2016b.

SAVIANI, D. Escola e democracia. $43^{a}$ ed. Revista. Campinas: Autores Associados, 2018.

SAVIANI, D. Educação Escolar, currículo e Sociedade: o problema da Base Nacional Comum Curricular. In: Movimento. Revista de Educação. Ano 03, número 04, 2016 a.

SAVIANI, D.; DUARTE, N. A formação humana na perspectiva histórico-ontológica. In: SAVIANI, D.; DUARTE, N. Pedagogia histórico-crítica e luta de classes na educação escolar. Campinas: Autores Associados, 2012. p. 13-35.

Recebido em: 27 de novembro de 2021.

Aprovado em: 23 de abril de 2021 .

Publicado em: 08 de maio de 2021. 